\title{
Factor structure, internal consistency and reliability of the Posttraumatic Stress Disorder Checklist (PCL): an exploratory study
}

\author{
Estrutura fatorial, consistência interna e confiabilidade do \\ Posttraumatic Stress Disorder Checklist (PCL): um estudo exploratório
}

Eduardo de Paula Lima, ${ }^{1}$ Sandhi Maria Barreto, ${ }^{2}$ Ada Ávila Assunção ${ }^{3}$

\begin{abstract}
Introduction: Posttraumatic stress disorder (PTSD) is an anxiety disorder resulting from exposure to traumatic events. The Posttraumatic Stress Disorder Checklist (PCL) is a self-report measure largely used to evaluate the presence of PTSD.

Objective: To investigate the internal consistency, temporal reliability and factor validity of the Portuguese language version of the PCL used in Brazil.

Methods: A total of 186 participants were recruited. The sample was heterogeneous with regard to occupation, sociodemographic data, mental health history, and exposure to traumatic events. Subjects answered the PCL at two occasions within a 15 days' interval (range: 5-15 days).

Results: Cronbach's alpha coefficients indicated high internal consistency for the total scale (0.91) and for the theoretical dimensions of the Diagnostic and Statistical Manual of Mental Disorders, 4th edition (DSM-IV) $(0.83,0.81$, and 0.80$)$. Temporal reliability (test-retest) was high and consistent for different cutoffs. Maximum likelihood exploratory factor analysis (EFA) was conducted and oblique rotation (Promax) was applied. The KaiserMeyer-Olkin (KMO) index (0.911) and Bartlett's test of sphericity $\left(\chi^{2}=1,381.34, p<0.001\right)$ indicated that correlation matrices were suitable for factor analysis. The analysis yielded three symptom clusters which accounted for $48.9 \%$ of the variance, namely, intrusions, avoidance, and numbing-hyperarousal.

Conclusion: Our findings provide additional data regarding the psychometric properties of the $\mathrm{PCL}$, including internal consistency, test-retest reliability, and factor validity. Results are discussed in relation to PTSD theoretical models.

Keywords: Posttraumatic stress disorders, validity of tests, reproducibility of results, statistical factor analysis.
\end{abstract}

\section{Resumo}

Introdução: O transtorno do estresse pós-traumático (TEPT) é um transtorno de ansiedade decorrente da exposição a eventos traumáticos. Entre as medidas de avaliação dos sintomas, destaca-se o Posttraumatic Stress Disorder Checklist (PCL).

Objetivo: Investigar a consistência interna, a confiabilidade temporal e a validade fatorial da versão do $\mathrm{PCL}$ em português, utilizada no Brasil.

Métodos: Participaram do estudo 186 indivíduos heterogêneos em relação a ocupação, características sociodemográficas, histórico de saúde mental e exposição a eventos traumáticos. O PCL foi aplicado em dois momentos considerando um intervalo máximo de 15 dias (intervalo: 5-15 dias).

Resultados: A consistência interna (alfa de Cronbach) foi adequada para a escala total $(0,91)$ e para as dimensões teóricas do Diagnostic and Statistical Manual of Mental Disorders, 4th edition (DSM-IV) $(0,83,0,81$ e 0,80$)$. A confiabilidade temporal foi alta e consistente para diferentes pontos de corte. A análise fatorial exploratória pelo método da máxima verossimilhança, com rotação oblíqua (Promax), foi realizada. O índice Kaiser-Meyer-Olkin (KMO) $(0,911)$ e o teste de esfericidade de Bartlett $\left(\chi^{2}\right.$ $=1.381,34, \mathrm{p}<0,001)$ indicaram que a matriz de correlações era adequada para análise fatorial. Os resultados indicaram três conglomerados de sintomas que explicaram 48,9\% da variância, a saber, revivecência, esquiva e entorpecimento-hiperexcitabilidade.

Conclusão: Nossos achados fornecem informações adicionais sobre as características psicométricas do $\mathrm{PCL}$, incluindo consistência interna, confiabilidade teste-reteste e validade fatorial. Os resultados são discutidos em relação a modelos teóricos de TEPT. Descritores: Transtornos de estresse pós-traumáticos; validade dos testes; reprodutibilidade dos testes; análise fatorial.

\footnotetext{
${ }^{1}$ Psychologist, Department of Social and Preventive Medicine, Universidade Federal de Minas Gerais (UFMG), Belo Horizonte, MG, Brazil. ${ }^{2}$ MD. Epidemiologist, Department of Social and Preventive Medicine, UFMG. ${ }^{3}$ MD. Ergonomist, Department of Social and Preventive Medicine, UFMG.

Submitted Aug 12 2011, accepted for publication Dec 13 2011. No conflicts of interest declared concerning the publication of this article.

Suggested citation: Lima EP, Barreto SM, Assunção AA. Factor structure, internal consistency and reliability of the Posttraumatic Stress Disorder Checklist (PCL): an exploratory study. Trends Psychiatry Psychother. 2012;34(4):215-22.
} 


\section{Introduction}

Posttraumatic stress disorder (PTSD) is an anxiety disorder associated with exposure to traumatic events. The most common PTSD symptoms are clustered into a three-dimensional structure: reexperiencing (criterion $\mathrm{B}$ ), avoiding and numbing (criterion $\mathrm{C}$ ), and increased arousal (criterion D). ${ }^{1}$ However, empirical investigations do not provide support to this three-dimensional model.2,3

Factor studies have yielded inconsistent results regarding PTSD structure. Inconsistencies are attributed to differences such as: 1) research designs, especially the factor analysis approach; 2) sample characteristics; 3) the types of traumatic events considered; and d) PTSD symptom measures. 4,5

Early PTSD factor structure studies were carried out using exploratory factor analysis (EFA), a descriptive technique widely used to group large covariance matrices into a smaller number of latent factors. ${ }^{6}$ The advantage of EFA over other techniques is the possibility to study the performance of items in each factor construct. More recent studies, in turn, have employed confirmatory factor analysis (CFA), an inferential technique. 3,7 The advantage of this approach is the possibility to test specific hypotheses about data structure and compare different theoretical models. However, CFA provides limited information about factor loadings. ${ }^{8-10}$

PTSD factor studies can be based on structured psychiatric interviews or self-report measures. Self-report instruments are preferred as a result of their fast application, convenience, and lower cost.8,11 One of the structured self-report measures most frequently used in PTSD is the Posttraumatic Stress Disorder Checklist (PCL), developed by Weathers et al. ${ }^{12}$ The PCL is a PTSD symptom inventory focused on non-specific traumatic events. It was developed for both military (PCL-M) and civilian (PCL-C) samples, and its psychometric properties were first investigated in war veterans. Early validation studies conducted by the authors indicated satisfactory levels of test-retest reliability, internal consistency, convergent validity, and diagnostic accuracy. Further studies using the original PCL version, applied to different samples, also showed adequate levels of reliability and diagnostic accuracy. ${ }^{13-17}$ Compared to other self-report measures, PCL has the advantage of evaluating the frequency and severity of all symptoms listed in the Diagnostic and Statistical Manual of Mental Disorders, 4th edition (DSM-IV). In addition, it is suitable for any type of traumatic event. ${ }^{8}$

Exploratory and confirmatory approaches used in factor studies evaluating the original $\mathrm{PCL}$, however, have yielded conflicting results. Studies using EFA identified two to four factors and different loading items for each factor. The authors of the PCL presented a model with only two dimensions: a first cluster including reexperiencing, avoidance, and hyperarousal items, and a second cluster comprising numbing and hyperarousal items. ${ }^{12}$ These results suggested that the structure of PTSD symptoms was not consistent with the DSM-IV model. Later, two other exploratory studies conducted with cancer patients also yielded results that were inconsistent with the DSMIV. Both studies suggest a four-factor structure, however with a non-homogeneous item distribution. ${ }^{8,11}$ The first study yielded a configuration focused on the factors reexperiencing, avoidance, numbing, and hyperarousal. ${ }^{8}$ The second study yielded one factor with reexperiencing items, a second related to hyperarousal, and two mixed factors: numbing-hyperarousal and avoidance-numbing. ${ }^{11}$

Studies using CFA found a more consistent structure and indicated the presence of three to four factors. The most common solution among such studies is the fourfactor. These studies also suggest underlying patterns of symptoms non-congruent with the DSM. 3,4,7,18-20

To date, only three studies have investigated the psychometric characteristics of the Portuguese language version of the PCL used in Brazil. In the first study, 234 firefighters and 378 police officers from different regions of Brazil were evaluated. ${ }^{21}$ Separate EFAs were conducted for each group and yielded a factor solution with three and four dimensions, respectively. Results obtained for the firefighters suggest a structure including reexperiencing, avoidance, and numbing-hyperarousal clusters. Police officer results were similar, except for the component hypervigilance (D4), which loaded as a single factor. The difference between the two groups was attributed to the nature of police work, i.e., to the fact that officers are constantly "on alert" or "on guard."

The second study used a sample of 103 victims of motor vehicle accidents and unexpectedly found a onedimensional configuration. ${ }^{22}$ In that EFA study, however, the instrument Likert scale had been expanded to 11 points from the original 5-point scale. Given the increased variability of responses, it is plausible that this change may have yielded a non-comparable version of the PCL.

The third study was conducted with 805 primary care patients living in a poor area of Rio de Janeiro. ${ }^{23}$ The sample was heterogeneous regarding sociodemographic characteristics and exposure to traumatic events. The authors used CFA to compare seven alternative PTSD models. Results suggested a four-factor structure including the following dimensions: 1) reexperiencing; 2) avoidance; 3) numbing; and 4) hypervigilance. A summary of the main results of EFA and CFA studies is presented in Table 1.

In summary, there is no consistent pattern regarding PCL's factor structure. For the Portuguese language version used in Brazil, difficulties in integrating different contributions 
Table 1 - Main results obtained in PCL construct validity studies

\begin{tabular}{|c|c|c|c|c|c|c|c|}
\hline \multirow{2}{*}{$\begin{array}{l}\text { Factor } \\
\text { analysis }\end{array}$} & \multirow[b]{2}{*}{ Study } & \multirow[b]{2}{*}{ Sample } & \multicolumn{5}{|c|}{ Results } \\
\hline & & & Factors & 1 & 2 & 3 & 4 \\
\hline \multirow[t]{6}{*}{ Exploratory } & Bringhenti et al. (2010), Brazil22 & MVA victims $(n=103)$ & 1 & - & - & - & - \\
\hline & Passos (2008), Brazil21 & Firefighters $(n=230)$ & 3 & $\mathrm{R}$ & $A$ & $\mathrm{~N}+\mathrm{H}$ & - \\
\hline & & Police officers $(n=343)$ & 4 & $\mathrm{R}$ & $A \quad$ & $\mathrm{H}$ (item 16) & $\mathrm{H}$ \\
\hline & Shelby et al. (2005), USA ${ }^{8}$ & $\begin{array}{l}\text { Women diagnosed with } \\
\text { breast cancer }(n=148)\end{array}$ & 4 & $\mathrm{R}$ & $A$ & $\mathrm{~N}$ & $\mathrm{H}$ \\
\hline & Smith et al. (1999), USA ${ }^{11}$ & $\begin{array}{l}\text { Bone marrow transplanted } \\
\text { adult patients }(n=111)\end{array}$ & 4 & $\mathrm{R}$ & $A+N$ & $\mathrm{~N}+\mathrm{H}$ & $\mathrm{H}$ \\
\hline & Weathers et al. (1993), USA ${ }^{12}$ & $\begin{array}{l}\text { War veterans of Gulf War } \\
(n=1,006)\end{array}$ & 2 & $\mathrm{R}+\mathrm{A}+\mathrm{H}$ & $\mathrm{N}+\mathrm{H}$ & - & - \\
\hline \multirow[t]{13}{*}{ Confirmatory } & Costa et al. (2011), Brazil ${ }^{23}$ & Primary care patients $(n=805)$ & 4 & $\mathrm{R}$ & A & $\mathrm{N}$ & $\mathrm{H}$ \\
\hline & Elhai et al. (2009), USA ${ }^{18}$ & Undergraduates - trauma- & 4 & 4 & $\mathrm{R}$ & $\mathrm{R}$ & A \\
\hline & & $\begin{array}{l}\text { specific }(n=218) \text { and trauma- } \\
\text { general groups }(n=234)\end{array}$ & A & $\mathrm{D}$ & $\mathrm{N}$ & $\mathrm{H}$ & $\mathrm{H}$ \\
\hline & Palmieri et al. (2007), USA ${ }^{7}$ & $\begin{array}{l}\text { Workers exposed to WTC } \\
\text { disaster }(n=2,960)\end{array}$ & 4 & $\mathrm{R}$ & A & $\mathrm{D}$ & $\mathrm{r}$ \\
\hline & Elhai et al. (2007), USA ${ }^{19}$ & $\begin{array}{l}\text { College psychology } \\
\text { students }(n=510)\end{array}$ & 4 & $\mathrm{R}$ & A & $\mathrm{N}$ & $\mathrm{H}$ \\
\hline & Shinka et al. (2007), USA ${ }^{24}$ & $\begin{array}{l}\text { Elderly survivors of the } 2004 \\
\text { Florida hurricane }(n=134)\end{array}$ & 4 & $\mathrm{R}$ & $A$ & $\mathrm{~N}$ & $\mathrm{H}$ \\
\hline & Krause et al. (2007), USA ${ }^{25}$ & $\begin{array}{l}\text { Women victims of intimate } \\
\text { partner violence }(n=801)\end{array}$ & 4 & $\mathrm{R}$ & $A$ & $\mathrm{D}$ & $\mathrm{r}$ \\
\hline & Palmieri et al. (2005), USA ${ }^{3}$ & $\begin{array}{l}\text { Women victims of sexual } \\
\text { harassment at work }(n=1,218)\end{array}$ & 4 & $\mathrm{R}$ & A & $\mathrm{N}$ & $\mathrm{H}$ \\
\hline & Marshal et al. (2004), USA 26 & $\begin{array}{l}\text { Young adults survivors of } \\
\text { community violence }(n=419)\end{array}$ & 4 & $\mathrm{R}$ & A & $\mathrm{N}$ & $\mathrm{H}$ \\
\hline & DuHamel et al. (2004), USA & $\begin{array}{l}\text { Women diagnosed with cancer } \\
(n=236)\end{array}$ & 4 & $\mathrm{R}$ & A & $\mathrm{N}$ & $\mathrm{H}$ \\
\hline & Simms et al. (2002), USA ${ }^{20}$ & $\begin{array}{l}\text { Military exposed }(n=1,896) \\
\text { and non-exposed to war } \\
(n=1,799)\end{array}$ & 4 & $\mathrm{R}$ & A & $\mathrm{D}$ & $\mathrm{r}$ \\
\hline & Cordova et al. (2000), USA & $\begin{array}{l}\text { Women diagnosed with breast } \\
\text { cancer }(n=142)\end{array}$ & 3 & $\mathrm{R}$ & $A+N$ & $\mathrm{H}$ & - \\
\hline & Asmundson et al. (2000), USA ${ }^{27}$ & $\begin{array}{l}\text { Patients with routine medical } \\
\text { problems }(n=349)\end{array}$ & 4 & $\mathrm{R}$ & $A$ & $\mathrm{~N}$ & $\mathrm{r}$ \\
\hline
\end{tabular}

have been attributed to the homogeneity of samples included in the two exploratory studies available. ${ }^{21,22}$

Therefore, the objectives of the present study are: 1 ) to investigate the factor structure of the PCL using EFA in a heterogeneous sample with regard to sociodemographic background, occupational characteristics, and exposure to traumatic events; and 2) to investigate the internal consistency and temporal reliability of the instrument.

\section{Methods}

\section{Participants}

The study sample comprised 186 volunteers recruited from three distinct groups: graduate students in the field of health care $(n=35)$, participants in first aid courses offered at the Belo Horizonte Fire Department $(n=121)$, and employees of a state-owned bank $(n=30)$.

\section{Instruments}

The PCL comprises 17 items that evaluate PTSD symptoms according to the diagnostic criteria of the Diagnostic and Statistical Manual of Mental Disorders, 3rd edition, Revised (DSM-III-R), which remained unchanged in the latest versions of the manual.1,28,29 Respondents should indicate how much they were troubled in the last month by the symptoms described using a Likert scale ranging from 1 (not at all) to 5 (extremely). The final score may range from 17 to 85 points. According to Weathers et al., the optimal cutoff 
to define the presence of PTSD is a total score $\geq 50 .{ }^{12}$ Those authors also suggest that the DSM-IV criterion can also be used for diagnosis, considering the presence of symptoms when responses are rated $\geq 3$ (moderately).

The Portuguese language version of the PCL used in Brazil was developed in 2004 specifically for civilian contexts. ${ }^{30}$ The semantic equivalence of this version was achieved over four steps including translation and backtranslation, formal appreciation of semantic equivalence, and pilot application in a target population.

Background and general information about mental health history and exposure to potentially traumatic events was collected using a structured self-report questionnaire. Sociodemographicbackground information included sex, age, marital status, number of children, years of education, ethnic group and monthly income. The following information was collected regarding mental health in the last 12 months: psychological or psychiatric treatment, use of psychiatric medications, and diagnosis of mood or anxiety disorders. The questionnaire also inquired about exposure to potentially traumatic events and non-traumatic stressors in the prior 12 months; these questions were framed in accordance with DSM criteria. ${ }^{1}$ Potentially traumatic events included hospitalizations due to serious health problems or accidents, death of close relatives, robbery, and assault. Stressful life events (non-traumatic stressors) included severe financial problems, relationship breakup, unwanted change of address, and social prejudice.

\section{Procedures}

Participants were informed about the aims and the voluntary nature of the study and were asked to sign an informed consent form prior to assessment. In both application sessions, participants responded to the questionnaires in the same classrooms where they would subsequently have class (health professionals and participants in first aid courses) or training activities (bank employees). During the first application (test), respondents were given the general questionnaire and the PCL. At the second application (retest), which occurred within 15 days of the test, participants were asked to answer the PCL only.

The research project was approved by the Ethics Committee of Universidade Federal de Minas Gerais (protocol no. 0387.0.203.000-10).

\section{Statistical analysis}

Analyses were performed using the Statistical Package for the Social Sciences (SPSS), version 17.0. An exploratory approach was adopted for factor analysis, to investigate the performance of each item of the Portuguese language version of the PCL used in Brazil. ${ }^{8}$

Internal consistency was assessed using Cronbach's alpha coefficients.

The Kaiser-Meyer-Olkin (KMO) test was performed to analyze the feasibility of factor analysis. This measure may vary between 0 and 1 ; high values of sphericity mean that the variables are correlated and the analysis is feasible. Bartlett's test of sphericity was also performed. EFA was used to assess the structure of the scale, using the maximum likelihood method with oblique rotation (Promax). Oblique rotation is suitable for the investigation of latent constructs for which one expects to extract correlated dimensions. ${ }^{31}$

In this study, the sample size $(n=186)$ yielded an item-to-participant ratio of $1: 11$, which is considered adequate for EFA. ${ }^{32} \mathrm{~A}$ scree plot and eigenvalues were used to establish the number of factors. The conservative criterion suggested by Hair et al. was applied during factor interpretation. ${ }^{9}$ Considering the sample size, a statistical power of $80 \%$, and a significance level of $5 \%$, only factor loadings $\geq 0.42$ were used when interpreting the findings.

The test-retest reliability of the PCL was assessed using the repeatability index and the Bland-Altman plot. ${ }^{33}$ The kappa index was also used to evaluate instrument reliability considering different cutoffs described in the literature. ${ }^{12,13,17}$

\section{Results}

The age of participants ranged from 18 to 58 years (mean \pm standard deviation $[S D]=39.9 \pm 10.1$ years). Most participants were female $(54.3 \%) ; 49 \%$ were single, $36.2 \%$ were married or in a stable relationship, and $12 \%$ were divorced. With regard to formal education, $44 \%$ had an undergraduate or graduate degree, $43.9 \%$ had completed high school, and $6 \%$ had only attended primary school. Sixty-three participants (38.9\%) reported a household income above U\$1,440 (equivalent to five Brazilian minimum monthly wages).

Most participants reported mixed ethnicity (42.6\%) or being white $(41.5 \%)$. Participants' occupations included several health professions $(32.5 \%)$, bank employees $(26.3 \%)$, military personnel $(18.4 \%)$, and others $(22.8$ $\%)$.

In relation to mental health history, $26.7 \%$ reported having undergone some type of psychological or psychiatric treatment in the last 12 months, and 23.6\% reported mood and/or anxiety disorders confirmed by clinical examination.

Exposure to potentially traumatic events was reported by $25.3 \%$ of respondents, as follows: death of a close 
relative $(10.8 \%)$, robbery $(9.1 \%)$, hospitalization due to severe health problems or accidents $(6.3 \%)$, and assault $(2.8 \%)$. Stressful life events were reported by $65.9 \%$ of respondents, in the following order of frequency: financial problems $(37.5 \%)$, social prejudice $(31 \%)$, relationship breakup $(25.7 \%)$, and unwanted change of address $(8.5 \%)$. Mean interval between the two application sessions was $7.65 \pm 1.89$ (range: 5 to 15 days).

Internal consistency, assessed by Cronbach's alpha, was high for the whole scale (0.91), as well as for the theoretical dimensions of the DSM-IV (criterion B $=0.83$, criterion $C=0.81$, and criterion $D=0.80)$.

The KMO index (0.911) and Bartlett's test of sphericity $\left(X^{2}=1,381.34, p<0.001\right)$ indicated that the data were suitable for factor analysis. Factor analysis indicated three

Table 2 - Three-factor solution and item factor loadings for the Portuguese language version of the Posttraumatic Stress Disorder Checklist used in Brazil

\begin{tabular}{lccc}
\hline & \multicolumn{3}{c}{ Factors } \\
\cline { 2 - 4 } Items & $\mathbf{1}$ & $\mathbf{2}$ & $\mathbf{3}$ \\
\hline 1 (B1) & -0.19 & $\mathbf{0 . 7 7}$ & 0.09 \\
2 (B2) & 0.05 & $\mathbf{0 . 6 3 5}$ & -0.01 \\
3 (B3) & -0.17 & $\mathbf{0 . 8 5}$ & 0.01 \\
4 (B4) & 0.16 & $\mathbf{0 . 5 0}$ & 0.23 \\
5 (B5) & 0.30 & 0.24 & 0.30 \\
6 (C1) & 0.01 & 0.11 & $\mathbf{0 . 6 7}$ \\
7 (C2) & 0.04 & -0.01 & $\mathbf{0 . 8 7}$ \\
8 (C3) & $\mathbf{0 . 4 8}$ & -0.24 & 0.18 \\
9 (C4) & $\mathbf{0 . 6 6}$ & -0.11 & 0.09 \\
10 (C5) & $\mathbf{0 . 7 4}$ & 0.01 & 0.01 \\
11 (C6) & $\mathbf{0 . 6 2}$ & 0.21 & -0.11 \\
12 (C7) & $\mathbf{0 . 7 1}$ & -0.04 & -0.02 \\
13 (D1) & 0.35 & $\mathbf{0 . 4 4}$ & -0.19 \\
14 (D2) & $\mathbf{0 . 5 8}$ & 0.26 & -0.06 \\
15 (D3) & $\mathbf{0 . 7 7}$ & -0.09 & 0.01 \\
16 (D4) & 0.21 & 0.31 & 0.06 \\
17 (D5) & $\mathbf{0 . 5 3}$ & 0.16 & 0.05 \\
\hline
\end{tabular}

Factor loadings in bold type were considered for cluster interpretation. factors with eigenvalues greater than 1.00 , which accounted for $48.9 \%$ of the total variance. The analysis of the scree plot also indicated a solution with three dimensions. Factor loadings for each factor are presented in Table 2.

EFA results indicated three factors. Nevertheless, examination of each item loading showed that the underlying structure differed from that originally presented in the DSM-IV. The dimensions obtained can be named as follows: 1) reexperiencing, 2) avoidance, and 3) numbinghyperarousal. An analysis of individual factor loadings also showed that items B5 (physical reactions when something reminded you of a stressful experience from the past) and D4 (being superalert) had low factor loadings.

Reliability evaluation considered the total scores obtained for the PCL and different cutoffs described in the literature. Final scores ranged from 17 to 75 (mean $\pm \mathrm{SD}=34.4 \pm 12.8$ ) for the test and from 17 to 72 $(32.7 \pm 13.4)$ for the retest. Differences in test vs. retest scores ranged from 0 to 30 points.

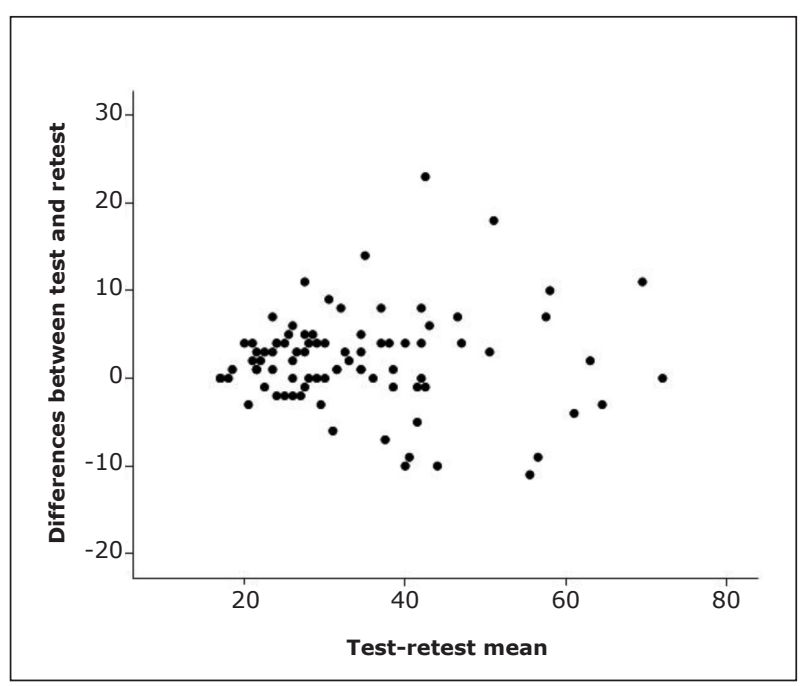

Figure 1 - Bland-Altman plot for the Portuguese language version of the Posttraumatic Stress Disorder Checklist used in Brazil (test-retest)

Table 3 - Kappa index for the Portuguese language version of the Posttraumatic Stress Disorder Checklist used in Brazil (test-retest) considering different cutoffs

\begin{tabular}{|c|c|c|c|c|}
\hline Criterion & Study & Kappa & SE & $95 \% \mathrm{CI}$ \\
\hline Total score $\geq 44$ & Blanchard et al. (1996) ${ }^{17}$ & 0.68 & 0.08 & $0.52-0.84$ \\
\hline Total score $\geq 50$ & Weathers et al. $(1993)^{12}$ & 0.82 & 0.07 & $0.68-0.96$ \\
\hline DSM-IV symptoms* & Weathers et al. $(1993)^{12}$ & 0.68 & 0.07 & $0.53-0.83$ \\
\hline DSM-IV symptoms* and total score $\geq 44$ & Ruggiero et al. (2003) $)^{13}$ & 0.67 & 0.08 & $0.50-0.84$ \\
\hline DSM-IV symptoms* and total score $\geq 50$ & Ruggiero et al. (2003) $)^{13}$ & 0.78 & 0.08 & $0.63-0.93$ \\
\hline DSM-IV symptoms ${ }^{+}$and total score $\geq 44$ & Ruggiero et al. (2003) $)^{13}$ & 0.69 & 0.09 & $0.52-0.86$ \\
\hline DSM-IV symptoms $^{+}$and total score $\geq 50$ & Ruggiero et al. (2003) $)^{13}$ & 0.71 & 0.09 & $0.53-0.89$ \\
\hline
\end{tabular}

$95 \% \mathrm{CI}=95 \%$ confidence interval; DSM-IV = Diagnostic and Statistical Manual of Mental Disorders, 4th edition; SE = standard error.

$\mathrm{p}<0.001$ for all comparisons.

* Symptoms scoring 3 (moderately) or higher were considered to be present.

+ Symptoms scoring 4 (quite a bit) or higher for items 1, 2, 9, 10, 12, and 15 were considered to be present. Symptoms scoring 3 (moderately) or higher for the remaining items were considered to be present. 
Figure 1 shows the Bland-Altman plot with the difference between each pair of test and retest scores compared with the mean of the same two scores. Graphical analysis suggests a considerable difference between the two scores, indicating that > 95\% of the observations remained within the limits of agreement. ${ }^{33}$ The repeatability index calculated $(12.26)$ corroborates the low reproducibility of scores.

The second strategy employed to analyze reliability considered the PCL as a dichotomous variable. The kappa index was calculated for different cutoffs used in the literature for total scale score, ${ }^{12,17}$ minimum number of symptoms according to the DSM-IV, ${ }^{12}$ and a combination of both. ${ }^{13}$ These results are presented in Table 3.

The kappa indices for the different cutoffs indicate good reproducibility. The cutoff considering a total score of $\geq 50$ showed the highest rate of test-retest agreement (kappa $=0.82)$.

\section{Discussion}

This study investigated the psychometric characteristics of the Portuguese language version of the PCL used in Brazil, and the results suggested compatibility of the Brazilian instrument with the original version. Factor validity, internal consistency, and temporal reliability were adequate, adding new information to semantic analyses performed earlier. ${ }^{30}$

A positive aspect of this study was that it included individuals heterogeneous not only with regard to their sociodemographic background and occupations, but also in relation to their mental health history, including PTSD symptoms. This variability avoided the biases discussed by Passos ${ }^{21}$, present when the samples are homogeneous with regard to background and occupational characteristics. Heterogeneous samples are important to guarantee the validity of any psychometric instrument. Our inclusion criteria ensured the possibility to generalize the evidence of validity here reported for the PCL. ${ }^{34}$

The evaluation of potentially traumatic events congruent with DSM-IV criterion A and non-traumatic stressful events proved to be advantageous to skirt the limits of uncertainty related to trauma definitions..$^{2,35}$ Finally, we believe that the heterogeneity of events experienced by participants adds further strength to this study.

Reliability was high for the different cutoffs considered, especially the cutoff suggested by the authors of the PCL. ${ }^{12}$ However, the Bland-Altman plot and the repeatability index indicated that the reproducibility of test and retest scores was low.
The analysis of reliability of psychometric measures using the approaches described above is not common in PTSD symptom scales. Previous studies employing $\mathrm{PCL}$ used only parametric correlations (Pearson) between different applications. ${ }^{12,13}$ However, correlation coefficients are only suitable for investigating similarities in response patterns. ${ }^{33}$ Research about the reliability of measures, in turn, is concerned with the magnitude of responses.

Considering the lack of analyses in the literature, it is not possible to compare the Bland-Altman plot and repeatability index results obtained for the Portuguese language version of the $\mathrm{PCL}$ used in Brazil with other versions of the PCL. Pearson's correlation coefficients between test and retest scores in this study suggest a similar performance to that of the original scale (rho = 0.90, p < 0.001).

Factor analysis identified a three-dimensional solution not congruent with the DSM-IV definition. Current DSM criteria describe reexperiencing and hyperarousal separately, and avoidance and numbing symptoms in a combined cluster. In this study, symptoms of avoidance and reexperiencing loaded into two dimensions, whereas items related to numbing and hyperarousal formed the third factor. The separation of DSM-IV criterion C into two dimensions is a general finding in PTSD factor studies. ${ }^{6}$ Numbing and hyperarousal items, in turn, appear in different ways in the literature. .,20,36 $^{2}$

Taylor et al. reviewed the first exploratory factor studies regarding PTSD structure. ${ }^{6}$ The authors assessed studies employing self-report scales and structured psychiatric interviews for the detection PTSD symptoms and found two main dimensions: intrusion and hyperarousal. For those authors, this two-dimensional solution is related to the theoretical model proposed by Foa et al., in which avoidance and numbing are separate mechanisms. ${ }^{37}$ Avoidance would be regulated by a conscious mechanism to avoid trauma-related stimuli (e.g., intrusions), while numbness would be the result of hyperarousal, involving more automatic mechanisms.

The results from our sample, which included 186 subjects, evoke the theoretical model mentioned above, which considered conscious mechanisms vs. automatic mechanisms criteria, to the extent that avoidance and numbing clusters loaded in different dimensions. ${ }^{37}$

A second possible interpretation is related to the findings of studies that specifically used the original PCL version. Confirmatory studies with four-factor models have indicated more consistent results. However, those studies suggest two models characterized by distinct patterns of symptoms: an emotional numbing model and a dysphoria model. The first model is the most commonly found in confirmatory studies and keeps the 
DSM-IV theoretical dimensions reexperiencing (B1-B5) and hyperexcitability (D1-D5), but splits criterion $C$ into avoidance (C1-C2) and numbing (C3-C7).4,7,19,24,26,27 The only confirmatory study conducted in Brazil suggests that this model provides the best fit for the PCL factor structure. ${ }^{23}$

The dysphoria model includes the clusters reexperiencing (B1-B5) and avoidance (C1-C2), and combines components of hyperarousal (D1-D3) and numbing (C3-C7) into one dimension of symptoms observed in several mood and anxiety disorders, called either negative affect, general stress, or dysphoria. ${ }^{20}$ In the dysphoria model, the remaining symptoms (D4D5) are kept in the hyperarousal cluster. ${ }^{18,25}$ Avoidance and reexperiencing clusters appear separately in both models. Therefore, divergence is present only with regard to the arrangement of numbing and hyperarousal items. In this study, the same pattern was observed for the first two dimensions. Conversely, numbing and hyperarousal loaded together, a pattern that differs from the two theoretical models.

It is important to note that the solution found in our study is quite similar to that found by Passos ${ }^{21}$ while studying professional firefighters in Rio de Janeiro. She also found three factors (reexperiencing, avoidance, and numbing-hyperarousal).

In relation to items with low factor loadings (B5 and D4), some considerations are necessary. Item B5 (physical reactions when something reminded you of a stressful experience from the past) was allocated under criterion D (hyperarousal) of DSM-III- $R,{ }^{28}$ and only in the subsequent version of the $D^{2} M^{29}$ was it transferred to criterion B (reexperiencing). Careful inspection of item B5 contents reveals that the item is multidimensional, resulting in a less stable performance in EFA studies. Another PCL exploratory study has also found problems related to $\mathrm{B} 5$ item performance, indicating multiple ${ }^{21}$ or low ${ }^{8,12}$ factor loadings. Item D4 (being superalert) also showed problems in many studies. ${ }^{8,11,21}$ Passos, in particular, found a quite unusual performance of this item in a sample of police officers. ${ }^{21}$ Moreover, authors such as Simms et al. have suggested that items D4 and D5 would be specific to PTSD, while other hyperarousal symptoms would be grouped with symptoms of numbing in order to create a dimension common to several psychiatric disorders. ${ }^{20}$

In the future, it would be useful to design and conduct more comparative studies regarding different PTSD theoretical models in order to improve the interpretation of these items. There are several criticisms to the construct presented in DSM-IV, most of them related to the definition of trauma (criteria $\mathrm{A} 1$ and $\mathrm{A} 2$ ) $^{38,39}$ and to the configuration of symptoms. ${ }^{20,35,36,40}$ Brewin et al., for instance, suggest that the DSM-V should focus on core PTSD symptoms and drop others related to mood and anxiety disorders. ${ }^{40}$ The results achieved in the present study corroborate these ideas and indicate that the current symptom structure lacks precision. Moreover, some of the symptoms seem to be poorly related to PTSD.

Finally, some limitations should also be highlighted. All the instruments used in the present study were self-reported. Despite the advantages of this type of instrument concerning time and costs, self-report measures are limited in the evaluation of psychiatric symptoms and exposure to traumatic life events. Future studies using structured interviews should be conducted.

\section{Conclusion}

Our results indicate that the Portuguese language version of the PCL used in Brazil has satisfactory internal consistency, reliability, and factor validity. The use of EFA for the investigation of the PCL measure in Brazil is adequate as a first approach. Notwithstanding, further studies using a confirmatory approach are needed to deepen the analysis of construct validity, as well as to establish a consistent cutoff point for the Brazilian population.

\section{Acknowledgements}

We would like to thank Prof. Carla Jorge Machado, $\mathrm{PhD}$, for her valuable suggestions to the manuscript, and Dr. Luiz Sérgio Silva, PhD, for his help in data collection procedures.

\section{References}

1. American Psychiatric Association. Diagnostic and Statistical Manual of Mental Disorders, 4th edition, Text Revision (DSMIV-TR). Washington: APA; 2000.

2. Rosen GM, Lilienfeld SO. Posttraumatic stress disorder: an empirical evaluation of core assumptions. Clin Psychol Rev. 2008;28:837-68.

3. Palmieri PA, Fitzgerald LF. Confirmatory factor analysis of posttraumatic stress symptoms in sexuality harassed women. J Trauma Stress. 2005; 18:657-66.

4. DuHamel KN, Ostroff J, Ashman T, Winkel G, Mundy EA, Keane TM, et al. Construct validity of the Posttraumatic Stress Disorder Checklist in cancer survivors: analysis based on two samples. Psychol Assess. 2004;16:255-66.

5. Cordova MJ, Studts JL, Hann DM, Jacobsen PB, Andrykowski MA. Symptom structure of PTSD following breast cancer. J Trauma Stress. 2000;13:301-19.

6. Taylor S, Kuch K, Koch WJ, Crockett DJ, Passey G. The structure of posttraumatic stress symptoms. J Abnorm Psychol. 1998;107:154-60. 
7. Palmieri PA, Weathers FW, Difede J, King DW. Confirmatory factor analysis of the PTSD Checklist and the clinicianadministered PTSD scale in disaster workers exposed to the World Trade Center ground zero. J Abnorm Psychol. 2007; 116:329-41.

8. Shelby RA, Golden-Kreutz DM, Andersen BL. Mismatch of posttraumatic stress disorder (PTSD) symptoms and DSMIV symptom clusters in a cancer sample: exploratory factor analysis of the PTSD Checklist-Civilian Version. J Trauma Stress. 2005;18:347-57.

9. Hair JF, Anderson RE, Tatham RL, Black WC. Multivariate data analysis. 5th ed. Englewood Cliffs: Prentice Hall; 1998.

10. Floyd FJ, Widaman KF. Factor analysis in the development and refinement of clinical assessment instruments. Psychol Assess. 1995; 7:286-99.

11. Smith MY, Redd W, DuHamel K, Vickberg SJ, Richetts P. Validation of the PTSD Checklist-Civilian Version in survivors of bone marrow transplantation. J Trauma Stress. 1999;12:485-99.

12. Weathers FW, Litz BT, Herman D, Huska JA, Keane TM. The PTSD Checklist $(\mathrm{PCL})$ : reliability, validity, and diagnostic utility. Annual Meeting of International Society for Traumatic Stress Studies; 1993 Oct; San Antonio, TX, USA.

13. Ruggiero KJ, Del Ben K, Scotti JR, Rabalais AE. Psychometric properties of the PTSD Checklist - Civilian Version. J Trauma Stress. 2003; 16:495-502.

14. Grubaugh AL, Elhai JD, Cusack KJ, Wells C, Frueh BC. Screening for PTSD in public-sector mental health settings: the diagnostic utility of the PTSD Checklist. Depress Anxiety. 2007;24:124-9.

15. Cook JM, Elhai JD, Areán PA. Psychometric properties of the PTSD Checklist with older primary care patients. J Trauma Stress. 2005;18:371-6.

16. Andrykowski MA, Cordova MJ, Studts JL, Miller TW. Posttraumatic stress disorder after treatment for breast cancer: prevalence of diagnosis and use of the PTSD Checklist - Civilian Version (PCL-C) as a screening instrument. J Consult Clin Psychol. 1998;66:586-90.

17. Blanchard EB, Jones-Alexander J, Buckley TC, Forneris CA. Psychometric properties of the PTSD Checklist (PCL). Behav Res Ther. 1996;34:669-73.

18. Elhai JD, Engdahl RM, Palmieri PA, Naifeh JA, Schweinle A, Jacobs GA. Assessing posttraumatic stress disorder with or without reference to a single, worst traumatic event: examining differences in factor structure. Psychol Assess. 2009;21:629-34.

19. Elhai JD, Gray MJ, Docherty AR, Kashdan TB, Kose S. Structural validity of the Posttraumatic Stress Disorder Checklist among college students with a trauma history. J Interpers Violence. 2007;22:1471-8.

20. Simms LJ, Watson D, Doebbeling BN. Confirmatory factor analysis of posttraumatic stress symptoms in deployed and nondeployed veterans of the Gulf War. J Abnorm Psychol. 2002;111:637-47.

21. Passos RBF. Estrutura fatorial da versão brasileira do PostTraumatic Stress Disorder Checklist - Civilian Version (PCL-C) [dissertation]. Rio de Janeiro: Universidade do Estado do Rio de Janeiro; 2008.

22. Bringhenti ME, Luft CB, Oliveira WF. Transtorno de estresse pós-traumático em acidentes de trânsito: validação de escala. Psico USF. 2010;15:193-203.

23. Costa MF, Mendlowicz MV, Vasconcelos AG, Berger W, Luz MP, Figueira I, et al. Confirmatory factor analysis of posttraumatic stress symptoms in Brazilian primary care patients: an examination of seven alternative models. J Anxiety Disord. 2011;25:950-63.

24. American Psychiatric Association. Diagnostic and Statistical Manual of Mental Disorders, 3rd edition, Revised. Washington (DC): APA; 1987.

25. American Psychiatric Association. Diagnostic and Statistical Manual of Mental Disorders, 4th ed. Washington: APA; 1994.

26. Berger W, Mendlowicz MV, Souza WF, Figueira F. Equivalência semântica da versão em português da Post-Traumatic Stress Disorder Checklist - Civilian Version (PCL-C) para rastreamento do transtorno de estresse pós-traumático. Rev Psiquiatr Rio Gd Sul. 2004;26:167-75.

27. Thompson B. Exploratory and confirmatory factor analysis: understanding concepts and applications. Washington: APA; 2004.

28. Tinsley HE, Tinsley DJ. Uses of factor analysis in counseling psychology research. J Couns Psychol. 1987;34:414-24.

29. Bland JM, Altman DG. Statistical methods for assessing agreement between two methods of clinical measurement. Lancet. 1986;1:307-10.

30. American Educational Research Association, American Psychological Association, National Council on Measurement in Educational. Standards for educational and psychological testing. Washington: AERA/APA/NCME; 1999.

31. McNally RJ. Progress and controversy in the study of posttraumatic stress disorder. Annu Rev Psychol. 2003; 54:229-52.

32. King DW, Leskin GA, King LA, Weathers FW. Confirmatory factor analysis of the clinician-administered PTSD scale: evidence for the dimensionality of posttraumatic stress disorder. Psychol Assess. 1998;10:90-6.

33. Foa EB, Zinbarg R, Rothbaum BO. Uncontrollability and unpredictability in post-traumatic stress disorder: an animal model. Psychol Bull. 1992;112:218-38.

34. Schinka JA, Brown LM, Borenstein AR, Mortimer JA. Confirmatory factor analysis of the PTSD Checklist in the elderly. J Trauma Stress. 2007;20:281-9.

35. Marshall, GN. Posttraumatic Stress Disorder Symptom Checklist: factor structure and English-Spanish measurement invariance. J Trauma Stress. 2004;17:223-30.

36. Asmundson GJ, Frombach I, McQuaid J, Pedrelli P, Lenox R, Stein MB. Dimensionality of posttraumatic stress symptoms: a confirmatory factor analysis of DSM-IV symptom clusters and other symptom models. Behav Res Ther. 2000;38:203-14.

37. Krause ED, Kaltman S, Goodman LA, Dutton MA. Longitudinal factor structure of posttraumatic stress symptoms related to intimate partner violence. Psychol Assess. 2007;19:165-75.

38. Weathers FW, Keane TM. The criterion A problem revisited: controversies and challenges in defining and measuring psychological trauma. J Trauma Stress. 2007;20:107-21.

39. Kilpatrick DG, Resnick HS, Acierno R. Should PTSD criterion A be retained? J Trauma Stress. 2009;22:374-83.

40. Brewin CR, Lanius RA, Novac A, Schnyder U, Galea S. Reformulating PTSD for DSM-V: life after criterion A. J Trauma Stress. 2009;22:366-73.

\section{Correspondence}

Eduardo de Paula Lima

Av. Alfredo Balena, 190/705

30310-100 - Belo Horizonte, MG - Brazil

E-mail: edpl@hotmail.com 